\title{
Poesia no contratempo: Samuel Beckett
}

\author{
Poetry in the odd time: Samuel Beckett
}

Marcos Siscar ${ }^{\star}$

\begin{abstract}
RESUMO
O trânsito entre as línguas é constitutivo da produção literária de Beckett. Muito embora sejam questões conhecidas da crítica beckettiana, a tradução e a autotradução ganham outra perspectiva se consideradas a partir da discussão sobre os gêneros, no contexto da passagem da poesia para a prosa. Beckett não é prioritariamente ou programaticamente um poeta. Ele opta por distanciar-se da tradição do verso, mas mantém a prática episódica do poema durante toda a extensão de sua obra. A hipótese deste artigo é que a passagem de Beckett àquilo que entende como obra é uma passagem relacionada à poesia, entendida como prática de escrita que tem historicidade e sentido próprios. "Poesia" e "tradução”, em Beckett, são nomes do acesso ao sentido, movimentos expostos ao contratempo.
\end{abstract}

Palavras-chave: Samuel Beckett; questão dos gêneros; tradução e autotradução.

\section{ABSTRACT}

The transit between languages is constitutive of Beckett's literary work. Although they are familiar issues of the Beckett studies, translation and self-translation get a new perspective if they are observed from the discussion about genres, in the context of the exchange of poetry for prose. Beckett does not intend to be primarily a poet. He chooses to take distance from the tradition of verse, but preserves the episodic practice of the poem throughout the length of his literary work. My hypothesis is that Beckett's passage to what he understands as his true work is a passage related to poetry, understood as a writing practice that has particular historicity and meaning. "Poetry" and "translation" are names of the access to meaning, movements exposed to the "odd time".

Keywords: Samuel Beckett; literary genres; translation and self-translation.

\footnotetext{
* Unicamp/CNPq
} 
á autores para quem a experiência de tradução não é apenas um acidente de percurso, mas parte integrante de sua produção literária. É caso de Samuel Beckett, cujo bem conhecido bilinguismo criativo tornou-se referência no assunto. Beckett escreveu em inglês ou em francês e, com raras exceções, ${ }^{1}$ traduziu ele próprio suas obras para a outra língua. O que está em questão aí, mais do que os aspectos biográficos que associam o percurso de Beckett a esses idiomas - ou ainda ao italiano e ao alemão - é a cumplicidade de destinos entre a escrita e a tradução.

Apesar de já escrever em inglês antes de iniciar sua produção em francês, o aproveitamento dos idiomas e de suas particularidades produz a sensação de que não há, para Beckett, uma língua original de escrita. O essencial é o uso relacional dessas línguas como matéria a partir da qual se dá uma experiência de escrita. Naturalmente, a fortuna crítica de Beckett aponta fases em sua trajetória como escritor, situações históricas e biográficas específicas, que modificam a compreensão do assunto. Mas é possível dizer que estamos diante de uma obra

1 Edith Fournier traduziu alguns textos de Beckett para o francês. 
Siscar, M.

Poesia no contratempo: Samuel Beckett

que assume sua condição bifida. As diferenças entre línguas e textos não é vista como um problema, mas, sim, como virtude do ponto de vista hermenêutico e poético, o que fica claro em sua atividade de "autotradução".

Esse modo de abertura literária relacionado às línguas faz da obra de Beckett, reconhecidamente, um caso especial. Mais do que isso, seria possível dizer que a tradução constitui para ele, explicitamente, uma escrita, um ato de produção de sentido; que ela encena singularmente o drama da "passagem ao sentido", repetindo uma expressão de Jacques Derrida. E, inversamente, que a escrita constitui um ato de tradução, um modo de relação.

A exemplo da porosidade sugerida por essa abertura à experiência do estrangeiro, a obra de Beckett também é uma obra feita de transições, de misturas, com seus veios de comunicação. Mas essas passagens e essas relações não existem sem algumas particularidades, sem algumas resistências, ou seja, sem alguma tensão.

E para dar destaque a esse aspecto conflituoso, ao invés de retomar a questão da tradução, gostaria de colocar em primeiro plano a relação que a obra de Beckett mantém com a ideia de poesia.

\section{A relação de Beckett com a poesia}

Não me refiro aqui exatamente à poesia em si, mas à ideia de poesia, à convenção poética ou, mais simplesmente, ao nome poesia, aquilo que o autor designa quando usa essa palavra "poesia". Quem sabe, no limite, não possamos entender esse processo como um caso de tradução.

Como se sabe, Beckett não é prioritariamente ou programaticamente um poeta. Pelo contrário, ele expressa reticências à retórica do gênero, desacreditando abertamente sua própria produção em versos. É possível encontrar, em suas cartas da década de 1930, ou seja, no "primeiro Beckett", muitas referências ao assunto, nas quais a questão do valor literário é colocada em primeiro plano. Falando sobre determinados textos que havia escrito, ele afirma que são

[...] poemas descritivos relativamente simples (em Francês) de episódios na vida de uma criança. Eu não sei o que eles valem. As poucas pessoas a quem os mostrei gostaram deles, mas são amigos. $^{2}$

(BECKETT, 2009a, p. 657)

Revista Letras,

2 As citações utilizadas neste texto são traduzidas por mim. A cada passo, indico em nota o texto de origem. "[...] quite straightforward descriptive poems (in French) of episodes in the life of a child. I do not know what they are worth. The few people I have shown them to liked them, but they are friends."

Curitiba, UFPR,

n. 95 9-23, 
De modo geral, é possível dizer que, nesse momento, Beckett tem uma teoria do valor literário perturbada pela constatação, relativamente convencional, do arbitrário do gosto. O horizonte dessa preocupação é uma ideia de qualidade literária, portanto de valor intrínseco, associada à virtude da originalidade, segundo a qual a escrita literária não deve ser a reprodução enfraquecida de modelos anteriores. É sabido, por exemplo, como Beckett precisou se descolar de Joyce e de Yeats, para experimentar sua realização como autor. Esse critério positivo do valor, entretanto, só poderá ter sucesso, em Beckett, graças a um procedimento negativo, que consiste no despojamento, no empobrecimento, por assim dizer, da linguagem do modelo.

Cabe constatar, inicialmente, que o autor pressupõe uma relação necessária entre as palavras e as coisas, ou ainda entre os poemas e as razões existenciais para escrevê-los. A esse propósito, comentando a tradução de um poema alemão (Ringelnatz) sugerida pelo amigo Axel Kaun, Beckett afirma que o esforço não valeria a pena, pois

Aquele pouco de necessidade que [os poemas] perdem no processo [de tradução] naturalmente só pode ser avaliado em relação ao que eles acabam perdendo já de cara, e devo dizer que esse coeficiente de deterioração me pareceu bastante insignificante, mesmo onde ele é mais poeta e menos versejador. $^{3}$

(BECKETT, 2009a, p. 517)

Trata-se aqui menos de uma teoria da tradução do que uma proposição sobre o valor literário. Se se considera que tradução envolve deterioração, prejuízo, perda, no estilo da conhecida máxima de Robert Frost ("poesia é o que se perde na tradução"), então a tradução de Ringelnatz tem um baixo coeficiente de deterioração, uma vez que não há muita poesia ali. Não chega a ser relevante a diferença entre aquilo que o original já perde, ele próprio, como poesia e aquilo que se perde dele na tradução.

Ora, o que se perde é exatamente aquilo que remete à necessidade. Parece-me que a teoria literária desse primeiro Beckett contempla uma visão de literatura relativamente convencional, ligada à velha discussão sobre o cratilismo, ou seja, sobre se há ou não uma relação necessária entre as coisas e seus nomes. Dela deriva, por extensão, uma hierarquia possível entre textos literários, que os ordenaria segundo seu valor, isto é, segundo sua capacidade menor ou maior de incorporar essa necessidade.

Essa desconfiança em relação à falta de motivação do signo literário (para formular o problema com sotaque saussureano) se mistura de modo sugestivo em

3 "The little that of necessity they lost in the process is of course only to be evaluated in relation to what they have to lose in the first place, and I must say that I found this co-efficient of deterioration quite insignificant even where he is most poet and least rhymester." 
Siscar, M.

Poesia no

contratempo: Samuel Beckett
Beckett com a própria motivação, no sentido psicológico: ou seja, com a vocação do escrever. Em carta de 1932, ele comenta aquilo que vê como deficiência em poemas que ele próprio havia escrito:

Sinceramente minha impressão era que [o poema] tinha pouco valor porque não representava uma necessidade. Quero dizer que, de certa maneira, era "facultativo" e que eu não teria ficado pior por não tê-lo escrito. Seria essa uma maneira muito imberbe de pensar sobre poesia? Quoi qu'il en soit [Seja como for; em francês no original] achei que era impossível abandonar essa perspectiva do assunto. Sinceramente de novo meu sentimento é que, cada vez mais, a maior parte da minha poesia, apesar de razoavelmente feliz na escolha dos termos, fracassa precisamente porque é facultativa. ${ }^{4}$

(BECKETT, 2009a, p. 133; grifos do autor)

A impossibilidade de abandonar tal perspectiva do assunto, suspeita de ser ainda demasiadamente preliminar, é significativa. Há em Beckett uma desconfiança de partida com relação ao caráter facultativo da escrita, que rapidamente se torna uma crítica ao caráter facultativo de sua produção poética, e talvez - eu acrescentaria - da própria poesia como gênero. Da desconfiança de que aquilo que se escreve não tem valor, de que a própria questão do valor pode não ser a melhor maneira de tratar de poesia, passaríamos a uma desconfiança geral em relação à poesia.

Tomando o problema por outro viés e antecipando uma espécie de conclusão, pode-se dizer que o fracasso da poesia em Beckett é aquilo que atribui necessidade à sua obra madura. Esse parece ser o ponto de partida, a razão necessária para que ele se coloque como escritor. "Poesia" (entre aspas) é nome da frustração que precede ou que determina certo tipo de realização literária; é, pois, instância de um revezamento literário, digamos, onde é preciso saber abandonar para poder prosseguir.

Vale dizer que esse esquema de relação com a poesia é um dos mais comuns e rotineiros de que se tem notícia na trajetória de escritores. Não deixa de ter alguma analogia com o caso de Joyce, embora, ao contrário de muitos romancistas, Joyce não se filie aos modelos realistas ou naturalistas mais comuns no romance. A diferença fundamental com essa tradição de romancistas-poetas-frustrados é que a "prosa" de Beckett não deixa de ter uma proximidade forte com a poesia

4 "Genuinely my impression was that it was of little worth because it did not represent a necessity. I mean that in some way it was 'facultatif' and that I would have been no worse off for not having written it. Is that a very hairless way of thinking of poetry? Quoi qu'il em soit I find it impossible to abandon that view of the matter. Genuinely again my feeling is, more and more, that the greater part of my poetry, though it may be reasonably felicitou in its choise of terms, fails precisely because it is facultatif."
Revista Letras,

Curitiba, UFPR, n. 95 9-23, jan./jun. 2017. ISSN 2236-0999 (versão eletrônica) 
que se produz hoje. O que explica que, ao mesmo tempo em que não é estudado como poeta, Beckett seja lido como poeta, por assim dizer.

É preciso lembrar, de passagem, que, para muitos poetas, a oposição em relação à poesia é um dos modos de relação com a poesia, uma maneira de "voltar" à poesia, estando claro que a volta não configura nunca exatamente um círculo: trata-se menos de um circuito fechado que um estar novamente às voltas com, isto é, de dar um outro giro no parafuso. Não há como voltar à poesia, após tê-la contestado, sem tomá-la entre aspas, explicitar sua transformação, assumir seus contratempos. $\mathrm{O}$ texto que resulta desse movimento deveria, portanto, configurar um tempo ímpar, que fosse também uma lacuna, um odd time - o tempo da tradução.

Em suma, quero sugerir que a política de gêneros em Beckett não é simples, mas bastante significativa do movimento interno de sua obra.

\section{$O$ critério de gênero}

À desconfiança sobre o valor de seus poemas, o primeiro Beckett alia uma desconfiança mais geral em relação à poesia como discurso enfático e artificioso, com tendência aos excessos formais, à erudição desnecessária, à obscuridade, vítima em suma de seu caráter não motivado, ou "construído" (BECKETT, 2009a, p.134). A poesia arrisca-se a ser um espaço de autocentramento, uma espécie de autonomia presunçosa, "que tem um fim em si mesma" ["that is an end in itself”] (BECKETT, 2009a, p. 134), em referência, como de praxe, à obra de Mallarmé. Trata-se do caso extremo de uma arte que estaria toda ela "em crise", enforcada por assim dizer no poste da modernidade ou da modernização.

Uso essa imagem de propósito. Ainda em sua correspondência, logo após qualificar a poesia de Mallarmé como "poesia jesuítica" [“Jesuitical poetry"] e após referir a sua própria integridade como a de um "protestante torpe de baixa igreja” [“dirty low-church P.”], Beckett usa essa imagem incisiva do enforcado, que remete a uma posteridade estéril:

Estou de luto pela integridade da emissão de sêmen de um pendu [enforcado; em francês no original], aquilo que encontro em Homero \& Dante \& Racine \& às vezes em Rimbaud [...]

(BECKETT, 2009a, p. 134-5)

Seguindo-se à crítica de Mallarmé, a afirmação parece referir-se à poesia como um todo. A poesia seria um espasmo de gozo, o esperma de um enforcado, seu sêmen, a excrecência escorrendo ainda fértil de um corpo morto, de uma

5 "I'm in mourning for the integrity of a pendu's emission of sêmen, what I find in Homer \& Dante \& Racine \& sometimes Rimbaud [...]." 
Siscar, M.

Poesia no

contratempo: Samuel Beckett

estéril descendência. Se a observação destaca-se pela sua crueza, o certo é que a "crise" é um topos da obra de Beckett e se manifesta na radicalidade de suas soluções de escrita, que são evidentemente muito mais complexas do que de uma simples diferença de gêneros.

Mas é interessante constatar que a questão se coloca dessa forma. Em relação ao assunto, Jean-Michel Rabaté se pergunta:

Em que medida ainda podemos estabelecer, em Beckett, uma oposição de "gêneros" diferentes como "poesia" e "romance"? Assim como para o último Joyce, não seria preciso chamar a tudo isso de "ficção" ou então de "poesia"?o

(In: ENGELBERTS, 1999, p. 75)

Discutindo a questão pela via do tratamento beckettiano do espaço "purgatorial" ("terceira zona" de uma "topografia fantasmática"; In: ENGELBERTS, 1999, p. 80), Rabaté coloca o problema para além das divisões tradicionais de gênero, para além do critério de gênero, o que é sem dúvida indispensável para se entender a obra de Beckett. ${ }^{7}$ Mas é preciso lembrar que, como toda atribuição de nome ("ficção", "poesia"), qualquer que seja, o risco sempre existe de repetir os equívocos de base, reeditando os fantasmas dessas topografias já estabelecidas. Ao mesmo tempo, é possível dizer que, uma vez o problema colocado, nenhuma recusa de nomeação pode ser poupada do mesmo inconveniente.

Não deixa de ser este o problema enfrentado por Marjorie Perloff (1982) quando coloca em primeiro plano o conflito que ela identifica entre a exclusão atual de Beckett das disciplinas de poesia e a importância que sua "lírica de ficção" (na expressão de Ruby Cohn) tem entre os poetas de língua inglesa. Independente da questão textual propriamente dita (ou seja, dos paralelismos e reiterações da escrita em prosa do autor, da exploração de certa aridez de linguagem, dos princípios de concisão e desfiguração muito comuns na tradição poética), o que significaria afinal estar "além do critério de gênero" quando a palavra "poesia" e a tradição associada a essa série ocupam o lugar daquilo que deve ser superado ou, eventualmente, recalcado?

Está claro que a designação para aquilo que faz a escrita literária de Beckett não é simples e perde bastante ao ser reconduzida a um gênero e a uma tradição. Mas não há razão para esquecer o diálogo que teve com os poetas surrealistas, a ponto de escrever uma espécie de manifesto, e o fato de ter sido tradutor de poesia: de Paul Éluard, de Rimbaud, de Apollinaire. Traduzindo em versos rimados e

Revista Letras,

6 "Dans quelle mésure peut-on encore opposer chez Beckett des "genres" divers tels que "poésie" et "roman'? Comme lorsqu'il s'agit du dernier Joyce, ne faut-il pas se résoudre à tout apeller ou bien 'fiction' ou bien 'poésie?".

7 Os organizadores da coletânea sobre Beckett vão mais longe, ao afirmar que a questão da "poesia" em Beckett fica mais bem colocada quando desvinculada dos poemas de Beckett e da "tradição dessa série" (ENGELBERTS et al, 1999, p. 7).

Curitiba, UFPR,

n. 95 9-23, 
sintéticos as máximas do moralista francês Sébastien Chamfort, originalmente escritas em prosa, Beckett cria um efeito irônico e curioso que não deixa de ter relação com sua visão do que é um poema, e do que um poema pode ou deveria fazer. A autoderisão certamente faz parte do programa, associando também por aí a produção de textos em versos à sua (digamos) produção principal. Apesar de ter feito uma espécie de opção geral pela "terceira zona", ou "terceira via" se quisermos, Beckett manteve uma atividade (pontual mas regular, marginal mas assumida publicamente) relacionada à poesia, no sentido mais clássico do texto em verso (definição, é claro, ela própria muito frágil em relação ao que é um "poema").

Do primeiro conjunto de poemas Whoroscope, de 1930 (no modelo eliotiano de The wast land, ou seja, do longo poema seguido de notas), até o último texto escrito em vida (o poema "Comment dire”, de 1988, já no hospital), passando por coletâneas de poemas organizadas e reeditadas de tempos em tempos, configura-se em Beckett uma relação que diz respeito a algo mais complexo do que a uma necessidade interna do texto. Alguns especulam se não haveria na produção em verso do autor uma ideia de laboratório para a obra escrita em prosa; poderíamos imaginar, ainda, algum tipo de fantasma relacionado à realização pessoal como escritor, sintoma da influência marcante que de fato recebeu dos autores e dos movimentos poéticos de fins do século XIX e começo do XX.

Analisar o sentido artístico e o sentido formativo da relação com a poesia demandaria um longo esforço descritivo, cujo pressuposto é o conhecimento aprofundado da obra do autor. Mas exigiria, além disso, uma disposição crítica que fosse além daquilo que autor soube dizer a respeito, inclusive associando à discussão problemas que nos interessam nos dias de hoje, que nos mobilizam na nossa relação com a literatura. No âmbito deste texto, limito-me a indicar o fato de que tal relação com a poesia é tratada pelo próprio autor de modo problemático, permanentemente cercada de hesitações ou de declarações de valor que não deixam de constituir-se, a meu ver, como uma espécie de resistência. Entre o que é e o que não é assumido como obra, instaura-se uma cena até certo ponto corriqueira das decisões estéticas de um escritor e de suas práticas de escrita. Mas essa cena tem também relação, a meu ver, com o destino daquilo que chamamos "poesia".

Em Beckett, a poesia aparece como elemento extemporâneo. Identificada criticamente com a suposta atemporalidade do objeto artístico (ou seja, fora do tempo), daquilo que supõe um estado de perfeição ou de autonomia, a poesia ocupa um lugar deslocado em relação ao contemporâneo movente da obra, isto é, a determinado desejo de passagem ao sentido. Para Beckett, a poesia parece não compartilhar o mesmo destino da obra desejada. Da perspectiva da constituição de sua obra, ela aparece como contratempo em relação à visão mais fina daquilo que é ou que poderia ser uma escrita literária. 
Siscar, M.

Poesia no

contratempo: Samuel Beckett

Nesse contexto, embora de modo indireto, a questão da poesia em Beckett tem um paralelo muito interessante com a questão da passagem à prosa, característica por exemplo da tradição crítica e poética estabelecida por Francis Ponge, na França. Mas está associada, sobretudo, à questão do idioma e à do sujeito do conhecimento. São fios de reflexão que permanentemente se entrelaçam.

\section{A leitura bilíngue}

A opção pela prosa, em Beckett, é análoga - cronologicamente, quase contemporânea - à passagem ao francês como língua de expressão literária. Há uma similaridade visível entre uma proposta cada vez mais clara de concisão e desfiguração, no nível da escrita, e um interesse decisivo pelo francês, descrito como "mais pobre", na esfera do idioma: "Escolhi escrever em francês porque o francês é uma língua mais pobre que o inglês". Nessa famosa anedota atribuída a Beckett, e confirmada em textos do autor, a diferença entre as línguas passa também pela diferença entre culturas e imaginários. Algo que é dito em uma língua nunca é exatamente o mesmo quando dito em outra língua. Tal passagem de Molloy, por exemplo, diz Beckett a um interlocutor, deveria ser colocada de forma muito diferente em inglês, pois o inglês seria uma língua mais "lisonjeadora" do que o francês. ${ }^{8}$ Escolher o francês, a língua mais pobre, é, portanto, escolher um modo de escrita que chama para si o despojamento, a desfiguração, a redução do idioma a seus elementos mais básicos, ou mesmo, metaforicamente, ao silêncio. Nesse sentido, depois de ter ido ao francês, a volta para o inglês deveria ser um exercício do mesmo tipo e não apenas a produção de uma simetria, isto é, de uma homologia textual.

Por isso, a autotradução, em Beckett, é um exercício que exige a reconfiguração da relação disjuntiva e hierárquica entre texto original e texto traduzido. Editorialmente, a atividade de autotradução suporia a publicação bilíngue de cada texto de Beckett (embora isso, estranhamente, não pareça ser comum) ${ }^{9}$. Mas a autotradução requisita algo mais: requisita uma leitura bilíngue, a leitura de um objeto bífido. Escrever prioritariamente numa língua estrangeira é colocar em primeiro plano o fato de que não há um lugar de partida estável; que é preciso sempre escrever duas vezes, traduzir duas vezes. De certo modo, são dois processos de tradução que estão em jogo, um em cada língua, uma língua sendo afetada pela necessidade da outra. Nesse sentido, o alijamento de

Revista Letras,

8 Como lembra Jean-Paul Gavard-Perret (In: FELS, 2009, p. 40).

9 O modo de publicação geralmente monolíngue de Beckett e o cuidado exegético mais comum em inglês não deixam, aliás, de ter correspondência com sua situação nas literaturas nacionais de cada espaço linguístico. De modo que o tratamento da questão linguística em Beckett é também, ou antes de tudo, uma questão de política literária e, em última instância, de política tout court.

Curitiba, UFPR,

n. 95 9-23, 
um estado de pertencimento linguístico ou literário originário é colocado em primeiro plano, tanto na "escrita" de um texto quando na sua "tradução".

Mais do que isso, se a escrita se revela prioritariamente em sua condição de expropriação, de "extemporaneidade", então podemos falar de uma dupla operação: num primeiro momento, paradoxalmente, trata-se de reconfigurar o texto, de assumir seu nascimento já derivado, construído pelo artifício de uma outra língua; num segundo momento, de explicitar as particularidades e os impasses desse texto já outro. Ou seja, no contexto da autotradução, a escrita vale tanto como reescrita quanto como releitura.

Reescrita e releitura: o duplo conceito não deixa de ter relação com a conhecida proposta de Haroldo de Campos (1992) da tradução como "criação" e como "crítica". Mas os pressupostos e as consequências aqui são distintos. Não estamos exatamente na esfera da originalidade criativa ou da singularidade crítica, de uma reconfiguração do efeito de primeiridade. Derrida (1974) aludia à tradução de Poe por Mallarmé pela via de um como se: a tradução soa de novo como se fosse pela primeira vez. Talvez pudéssemos rever a proposição, sem desvirtuá-la: em Beckett, eu diria, o texto soa em sua língua como se já fosse tradução. Ou seja, o "re" da reiteração faz com que, desde a primeira vez, o texto imponha uma reflexão sobre a tradução, sobre sua condição relacional. Impõe já à singularidade supostamente primeira uma condição de espaçamento ou, como poderíamos acrescentar, na chave temporal, de extemporaneidade. Do mesmo modo, em outro nível, o re- da re-volta beckettiana contra a noção de atemporalidade ("poesia") se torna um elemento básico da passagem ao sentido, trazendo consigo o sentido da viagem.

Propor uma leitura bilíngue é falar não de uma expansão da leitura à página dupla, ou a um jogo de colunas textuais, mas de uma co-implicação ativa, na qual um texto lê (ou deslê) a língua do outro.

\section{O odd time da tradução}

Um caso de autotradução que apenas indico de passagem, e de modo extremamente sintético, é o de um poema escrito em 1974, em francês ("hors crâne seul dedans"), e publicado em 1975, na tradução em inglês ("Something there"):

$$
\begin{aligned}
& \text { hors crâne seul dedans } \\
& \text { quelque part quelquefois } \\
& \text { comme quelque chose } \\
& \text { crâne abri dernier } \\
& \text { pris dans le dehors } \\
& \text { tel Bocca dans la glace }
\end{aligned}
$$


Siscar, M.

Poesia no contratempo: Samuel Beckett l'oeil à l'alarme infime

s'ouvre bée se rescelle

n'y ayant plus rien

ainsi quelquefois

comme quelque chose

de la vie pas forcément

(BECKETT, 2009b, p. 64)

\section{Something there}

something there

where

out there

out where

outside

what

the head what else

something there somewhere outside

the head

at the faint sound so brief

it is gone and the whole globe

not yet bare

the eye

opens wide

wide

till in the end

nothing more

shutters it again

so the odd time

out there

somewhere out there

like as if

as if

something

not life

necessarily

(BECKETT, 2009b, p. 65)

A propósito desses textos, seria preciso pensar no jogo interioridade/ exterioridade como questão que envolve a percepção que o sujeito tem de si mesmo e daquilo que ele experimenta. Mas a oposição dentro/fora não deixa

Revista Letras,

Curitiba, UFPR,

n. 95 9-23,

jan./jun. 2017.

ISSN 2236-0999

(versão eletrônica) 
de remeter ao próprio jogo entre o texto escrito e o texto traduzido, em sua cumplicidade filosófica de coisas.

O primeiro verso do texto francês, de uma complexidade muito grande, envolve uma implicação entre fora e dentro. Resumidamente, pode-se dizer que aquilo que está preso na exterioridade (o crânio) se manifesta na condição de figura da interioridade ("único dentro" ou "sozinho dentro"). O horizonte dessa ambivalência é um "abrigo último", tanto quanto o espelho pode ser o lugar da morte do sujeito. $\mathrm{O}$ inferno da experiência subjetiva vem junto com uma citação de Dante, que se refere a Bocca, personagem histórico que a Divina Comédia encontrado no inferno, com a cabeça para fora do gelo. Em francês, "glace" é tanto gelo quanto espelho. E, de fato, o crânio preso no gelo pode ser também, aqui, de modo mais banal, um crânio visto num espelho. $\mathrm{O}$ crânio do poeta sai do espelho como o de Bocca sai de seu gelo/espelho ("glace"). Refletir é o lugar infernal do sentido, ou seja, daquilo que não chega a fazer sentido, nem ao menos alegórico.

O poema em francês tem divisão estrófica regular e um padrão rítmico reconhecível, já que os versos oscilam entre 5 e 7 sílabas, se contraindo e se expandindo duas vezes no poema. Já o poema em inglês implode essa organização formal. Revela, por assim dizer, o seu convencionalismo. Apesar de manter visível a divisão estrófica, aparenta desmontar sua relativa simetria. Elimina a citação erudita e pulveriza a frase até chegar a seus elementos gramaticais mínimos. Além disso, aprofunda a dissipação da imagem, no sentido retórico (da comparação, por exemplo), que já está em processo no poema francês. É um exemplo típico de desaparição de imagem ou de desfiguração, ${ }^{10}$ ou seja, da passagem de uma retórica da imagem para a aridez dos elementos gramaticais mínimos da língua. A essa desfiguração corresponde também, como eu acrescentaria, a passagem do fantasma do lirismo, que reflete o próprio corpo (e que tenderia a transformá-lo em alegoria da condição existencial), na direção de um discurso dialogado, teatral de certo modo. O como se ("as if") da tradução aparece aqui de modo explícito, no eco com "como alguma coisa" ("comme quelque chose").

No poema em francês, há uma radicalidade no esvaziamento da condição de sujeito e de sua capacidade alegórica (não necessariamente "alguma coisa" tem a ver com a "vida"). Esse esvaziamento é reconfigurado no segundo poema como se, para ser descrito, devesse ser reescrito, enfatizado. Reescrever, neste caso, é explicitar não apenas aquilo que o primeiro poema tem de característico, mas também aquilo que ele indiretamente confirma. Como se a tradução fosse um modo tanto de leitura quando de crítica, de explicitação daquilo que fica em segundo plano: uma forma talvez de radicalização, de expansão da lógica do primeiro texto. Quando falo de lógica do primeiro texto remeto tanto ao projeto de sentido desse texto quanto ao movimento que ele permite fazer para além

10 Há na poesia de Beckett, segundo Jean-Paul Gavard-Perret (2001, p. 35), a "preocupação de eliminar todo elemento figurativo" ["souci d'élimination de tout élément figuratif"]. 
Siscar, M.

Poesia no

contratempo: Samuel Beckett
Revista Letras,

Curitiba, UFPR, n. 95 9-23, jan./jun. 2017. ISSN 2236-0999 (versão eletrônica) de si, no mesmo sentido mas já fora do seu escopo - radicalizando portanto o ponto de vista do texto até o ponto em que esse movimento permite revelar os elementos contraditórios que compõe a sua lógica, isto é, os seus impasses. Uma re-leitura supõe, portanto, não apenas uma explicitação do projeto de sentido, mas também daquilo que o texto deveria se liberar para poder tornar-se aquilo que gostaria de ser.

A relação com a temporalidade no poema é exemplar desse processo, uma vez que, em francês, o valor da locução adverbial “quelquefois”, repetida duas vezes no poema, se altera, fazendo conviver um indefinido particular ("certa vez") com um indefinido genérico ("por vezes"). Já no texto inglês, a brevidade definida pelo rumor de um curto instante ("at the faint sound so brief") se especifica na última estrofe como um "odd time". A expressão "at odd times", no plural, seria uma forma mais próxima, ainda que curiosa, de "quelquefois". No singular ("the odd time"), ela parece remeter mais propriamente a um instante preciso, que é também um tempo de qualidade estranha e ímpar ("odd"). "Odd time" é, igualmente, em música, um tempo inusual, irregular, que se associa a uma quebra do padrão rítmico. Traduzir "quelquefois" por "the odd time" envolve a constatação de que o genérico, que é condição do alegórico, não se sustenta sem uma temporalidade inusual, uma tensão rítmica, por assim dizer.

Poderíamos enxergar esse estranho tempo como algo que, fazendo a leitura da metáfora espacial, pretende associar a ela a complexidade temporal, uma estranha temporalidade. E o faz radicalizando por assim dizer a problemática temporal do texto francês. Ao trair "quelquefois" (ao desviar-se de seu sentido imediato), a tradução acaba traindo (denunciando, explicitando, revelando) aquilo que há de extemporâneo em seu cálculo alegórico. Como o espaço da especularidade, o tempo é um tempo que, ao debruçar-se sobre si mesmo, revela-se excêntrico, estranho e sem centro. Um outro tempo ou, mais especificamente, um contratempo, um odd time.

\section{Traduzir-se em poeta}

Se a tradução é a cena (ou a "cerimônia”, como diz Michel Deguy; 1981, p. 35) do devir-texto do texto, poderíamos dizer que a relação com a poesia, em Beckett, é a cena do devir-poeta em Beckett. Ou seja, por caminhos complexos, que colocam em tensão sua ideia e sua prática de poesia, seria possível dizer que o tratamento da poesia e do poema em Beckett revela indiretamente, nos seus contratempos, o escritor que Beckett desejaria ser. Assim como a tradução, a poesia deveria ser vista, neste caso, como extemporaneidade reveladora, antes do que como anacronismo superado.

Haveria o que se dizer sobre a tradução como modo da aproximação ou da comparação, mas também como forma de aceleração dos diferentes tempos de uma obra (de suas ilusões de contemporaneidade, ou dos anacronismos críticos 
que constituem sua interpretação). Até por isso, talvez uma leitura de Beckett nos permita pensar que a passagem ao sentido, envolvida no ato da tradução, não é um acesso como qualquer outro, uma mediação em geral. Ou seja, que, retomando a questão da tradução, não se trata apenas de confirmar, digamos, uma tese genérica sobre o acesso, sobre a "passagem ao sentido". Trata-se também de colocar em primeiro plano determinada prática da passagem, sua estética e sua política.

Talvez isso possa ser dito, igualmente - como espero ter ao menos ter sinalizado -, no caso da poesia. E a esse propósito, num segundo momento, seria necessário dialogar com a apropriação feita da questão poética por filósofos que, procurando discernir os movimentos complexos do "poético", buscam descolar-se da poesia entendida como fenômeno restrito, interessado em questões "regionais", mergulhado nas eventuais trivialidades da sua tradição. Preferiria pensar, como acabo de dizer sobre a tradução, que a poesia não é uma mediação qualquer. A cena da obra de Beckett pode ser descrita justamente como uma passagem ao sentido relacionada à poesia, como prática histórica, com sua temporalidade e suas convenções, mas também com seu potencial de indefinição, de impropriedade, que abalam a própria estrutura do nome.

Algo se torna pensável aí, a partir dessa matéria e dessa "tradição", na sua contingência e na sua mundaneidade. Não é possível excluir de antemão, em nome da recusa à lógica de gênero ou em nome da suspensão filosófica, a necessidade crítica do poema. Prefiro ver "poesia" e "tradução" como nomes possíveis do acesso, odd names (para fazer um jogo de palavra com odd time) do acesso, ou seja, nomes possíveis de uma relação com o contratempo. 
Siscar, M.

Poesia no

contratempo: Samuel Beckett
Referências

BECKETT, Samuel. The letters of Samuel Beckett, v. 1, 1929-1940. Ed. Martha Dow Fehsenfeld e Lois More Overbeck. New York: Cambridge Univ. Press, 2009a. and Faber, 2009b.

Select poems 1930-1989. Ed. David Wheatley. London: Faber

CAMPOS, Haroldo de. "Da Tradução como Criação e como Crítica", in Metalinguagem \& Outras Metas. São Paulo: Perspectiva, 1992.

DEGUY, Michel. Donnant donnant. Paris: Gallimard, 1981.

DERRIDA, Jacques. Glas. Paris: Galilée, 1974.

ENGELBERTS, Matthijs; BUNING, Marius; HOUPPERMANS, Sjef. Poetry and Other Prose. Amsterdam/Atlanta: GA, 1999.

FELS, Laurent. Regards sur la poésie du XXe siècle. Tome 1. Namur (Bélgica): Les Éditions Namuroises, 2009.

GAVARD-PERRET, Jean-Paul. Beckett et la poésie: la disparition des images. Paris: Éditions le Manuscrit, 2001.

PERLOFF, Marjorie. "Between verse and prose: Beckett and the new poetry".

RABATÉ, Jean-Michel. "Beckett et la poésie de la zone (Dante...Apollinaire. Céline..Lévi)”. In: ENGELBERTS, Matthijs et als. Poetry and Other Prose. Amsterdam/Atlanta: GA, 1999.

Submetido em: 09/10/2016

Aceito em: 22/12/2016

Revista Letras, Curitiba, UFPR, n. 95 9-23, jan./jun. 2017. ISSN 2236-0999 (versão eletrônica) 